\title{
On Community Economy: Theory and Model
}

\author{
Haiying Ma \\ School of Economics, Northwest University for Nationalities Lanzhou (730124), P.R.China \\ Ixmahaiying8888@163.com
}

\begin{abstract}
Keywords: Community; Community economy; Model; Theory
\end{abstract}
\begin{abstract}
Community is the product of social and economic development, at the same time, it is the basic constitution of the city as well. As the division of labor between agriculture and handicraft industry as well as the revolution of the industrial technology, many labor migrate to the cities. The community, which is connected with the division of labor and contract, plays the unique economic function of building city. community plays a unique micro-economic role of how to develop urban functions and promote economic growth. This paper which takes community elements as the starting point of community economic structure, summarizes and outlines the definitions of community, and discusses the methods of researching community economic theory.
\end{abstract}

\section{Introduction}

Along with the growth of the world economy, many kinds of communities are formed in developed countries. On the one hand, it is due to the revolutionary changes brought by the early socialism that people request for additional benefits and to improve workers wages and living conditions. On the other hand, it is the inevitable result of economic development. The specific division of labor requests micro enterprises not only to face the traditional mode of production, but also to face the market of consumption subject to improve the production and management activities. It is the requirement of the development of market economy that as the basic unit of the country, community shows its own unique economic charm. various productions and business activities of the community members can not only reflect the efficiency of economic resources allocation, but also make a positive evaluation of economic policies. This is the significance of researching community economy in developed countries.

\section{Introduction to Community}

The Meaning of Community. The World Health Organization gathered experts who are professional in health care of community in 1974, to define the function of community health---Community is a social groups in a fixed geographic range whose members has a common interest, known to each other and contact with each other, exercise social functions, create social norms. And community is the formation of unique value system and social welfare. Each member is integrated into a larger community through family, neighbors, and community. In the early research of community, a book called Social customs and Legal society(1887)written by a famous German sociologist called Tonnies which mentioned that community is based on kinship and kinship, and formed the social union, in this joint summary, rational intention and nature will be mutual dependence, the individual has the strong sense of belonging. The American sociologist Spectroscopy referred to the community as a group of people organized around a certain geographic area in his book . Japanese sociologist Yokoyama Neo said that 'The community has a certain space, it is a comprehensive living community' in his book Introduction to sociology. To achieve the common goals, individuals and communities are combined, but the association of molecules is just to meet some special interest or to reach a certain special purpose, so personal and association can only sustain part of or one-side relationship. Ye Jinsheng (1997) from two aspects which are the community economic function and social function, thought that 'communities should be within a certain geographic area, the breath of people's learning living and working is an orderly space. And community is the formation of the city and have a common regional 
culture, customs, beliefs, values, consumption habits, infrastructure, economic and social life of the local environment, and is between society and organizations (including community associations between entities)'.

The above definitions of community contain the following four meanings: 1.Community always occupy a certain combination of local, regional or geographical space. 2.The appearance of community is inseparable from certain populations, the quantity of population, the density of the distribution and the quality of the population, all these aspects are important when people examine their community. 3.Due to some common interests, common problems, and common needs to combine, people who lives in the community produce and do some other activities. 4 . The central content of the community is the social activities of people in the community and their interactive relationship.

This paper try to define the meaning of community from the perspective of Economics. The community should be in a certain region, the overall social economic relations which is connected with the division of labor and contract, and in order to seek the maximum common interests. The emphasis on regional character is because the distribution pattern of the geographical space is influenced by the community economy. The social and economic relations between the division of labor and the contract is to show that the community residents are the social units formed by the common interests, and to seek the maximization of common interests.

The Basic Concept of Community Economy. At first, what is emphasized is that under the market mechanism, community economic activities can not only reflect the urban community of geographic spatial distribution but also the performance in the community competition, cooperation and conflict in the process of social interaction, and is an effective way to allocate resources. Certain community refers to a community which has a certain regional space, that is, between the society and the community. Resources of material form and value form include tangible assets, funds, and intangible assets (technology, patents), etc. With the market mechanism, the restructured resources plays a fundamental role of gaining the benefits from resources in the reallocation. The author thinks that the community economy should include the following features.

Community economic activities emphasize the influence of the geographical spatial pattern on the economic production activities; Choices of common social interests or common social preferences, that is community residents prefer to choose someplace with more perfect infrastructure, good service system, and external living conditions for coordination of work and living environment.

Theoretical Framework of Institutional Economics. we regard community economic research as the process of economic and social studies. The impact of this unique economic organization on the economy tends to coordinate the relationship between economic and social justice.Here are community economic research methods.

The first is to reduce the level of abstraction. This method enables the modeling of stages to carry out with the model gradually close to reality. At the same time, it will not lose the simple mode of guidance. The second is the framing effect, which reflects the combined effect on the rational choice and the environment definition. The third is the social production function of the general human goals. The goals of social production mode will be allowed to go into the preference analysis tool.And social production function reveals that under what conditions a person will think that social recognition, individuals to avoid loss and material benefits of production is extremely important.These directions substantially reduce the range of possible governance structures.Because of the trend that can be observed, different governance may be converging, because they must be united in the economy. The last is the conclusion of the contract. Only by converging to a common relationship between people's social and economic model in the contract, the degree of difference between the subjective reason and the frame effect may be extremely intelligent (i.e. opportunism). The convergence of researching community has gradually become a more scientific and forward-looking theoretical starting point,and the characteristics of community economic theory should be emphasized in the study of community economy theory in order to study the influence on people's selective behaviors to other individuals and social economic environment. In the model of community economic, the optimal population scale, community welfare, community public goods production and supply are all included. 


\section{Economic Theoretical Model}

Here the author will not introduce the theory of public choice any more, but the relevant part will be put forward in the concrete analysis. As a part of the community economic resources, the public products and the intermediate products must be involved in the problem of market externalities.

Introduction to Public Choice Theory. The demand and supply of public goods are the center of public economic theory research.There are many definitions of public goods, the author makes a chart of the distinction. The focus of this paper is on the supply of mixed goods which is non-exclusive, or the supply of mixed goods that is non-competitive but exclusive. In the production of intermediate products, it is assumed that the market information is complete, and the two sectors to provide products for the community residents can be replaced by each other, that is to say, there is efficiency. (Buchanan, 1970; Linda, 1976; Arrow, 1992, etc.)

Optimal Community Size. When the consumer preference and the production technology are convex, there will be a price system.Each enterprise's production plan and each family's consumption bundle meet the following conditions in the popular price: Each commodity supply is equal to demand; Companies seeking the maximum profit under the specified production set;

In this paper, the Tiebout Model is explained with reference to this point of view. Suppose firstly that the city is isolate. Second, there are a large number of communities in the city. Third, the population in the community can flow freely. Fourth, the family endowment of community residents will not change with the increase of education investment. Fifth, the internal city is a perfect competitive market. Sixth, the output level of public goods is in line with Nash equilibrium. Seventh, when individual makes migration decisions, he masters the complete information. Eighth, community government determines the level of public expenditure through the collection of personal income tax, that is, the financial basis of competition. Ninth, private sector can replace the public sector to provide public goods supply. Tenth, there's no level difference of the land, and the rental profit is zero.

From the assumption six and ten, we can conclude that the public sector can be replaced by the supply of public goods in the private sector, that is $\mathrm{MRSxy}=\mathrm{MC}=\mathrm{P}$, in other words, the marginal cost of public goods equals to the equilibrium price in the market.From the assumption eleven we can come to the individual utility function, that is $\mathrm{U}=\mathrm{U}(\mathrm{i})$. At this time,the market is completely a competitive market, so the equilibrium price will be realized,that is $\mathrm{P}=\mathrm{MC}$. The output function of the public product is $\mathrm{Q}=\mathrm{pq}$. The total utility of community residents as a function of demand of public products will achieve the equalization of public goods within the community, namely $Q=\sum U(i) p=M U$.

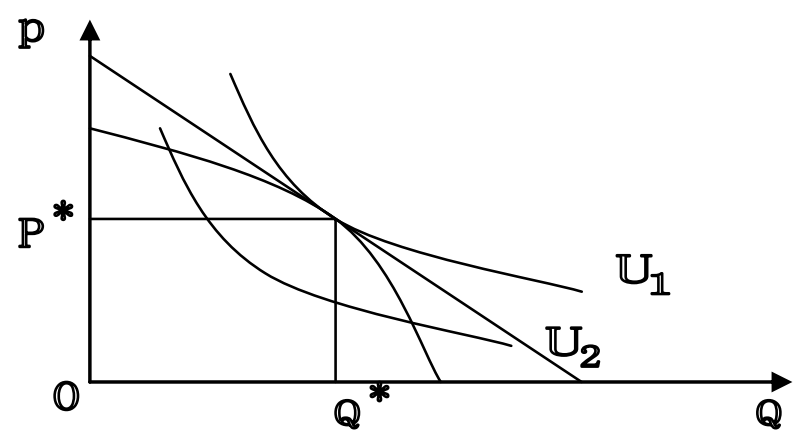

Figure 1

As shown in the Fig. 1, P represents the price of public goods, Q represents the public product quantity, $U$ represents the collective utility indifference curve, the individual utility can be used indifference curve $U$ to represent. Different utility levels lead to different output levels of public product. Under the condition of perfect competition market, the supply and demand of public goods will produce the intersection point between different utility levels, that is, the balance. In terms of individual utility and collective utility, it should be noted that it is the income differences leads to different combinations of public products and household products consumption and the formation of 
utility in different locations. This also shows that under the condition of income difference, different income levels produce different public goods supply level. And $\mathrm{F}(\mathrm{x})=\mathrm{U} \rightarrow \mathrm{P}=\mathrm{MC}$. It is believed that different utility levels result in different outputs. When the utility level is low, the production boundary of the enterprise is also very small. But at this time, mixed product scale were limited, namely the enterprise marginal cost is equal to the equilibrium price. Further derived, assuming that the number of community residents will increase with the population migration but the production scale of public goods remains unchanged, with the increase in the number of public goods consumption and portfolio choice, the community will reach the maximum scale of the community population at the given level of supply.

Suppose that $S$ represents a combination of consumption, $N$ represents the number of communities, $\mathrm{AC}$ represents the average cost of public goods production, $\mathrm{MC}$ represents the marginal cost of public goods production, $\mathrm{W}$ is the actual wage. We can derive from the eighth assumption that $\mathrm{w}=\mathrm{W}(1-\mathrm{t})$. Under the condition of competitive tax, the utility of the consumption portfolio can be subtracted from the rest of the tax revenue, at this time, the $t$ represents the tax rate, $w$ represents the actual income. Under the condition of complete market competition, the production function of public goods is $\mathrm{Q}=\mathrm{pq}$. At this point, the demand function can be expressed by $\mathrm{F}(\mathrm{N})=\mathrm{NW}$, that is, the number of community members multiplied by wages. Thus there is $\mathrm{Q}=\mathrm{NW}$, namely supply demand balance. In the intersection (short-run equilibrium) of the marginal cost and the average cost of public goods production, the number of community members will reach the optimal conditions under the demand function. Just as shown in the Fig. 2.

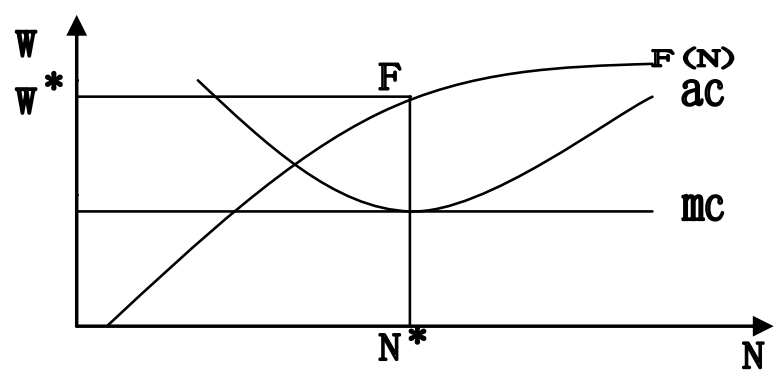

Figure 2

$\mathrm{N}^{*}$ represents the optimal population, and $\mathrm{W}^{*}$ represents the equilibrium wages.

Further assume that the community production function as the AK function, this time demand can be expressed as $\mathrm{D}=\mathrm{N}^{\wedge} \mathrm{r}^{*} \mathrm{~W}$ ( $\mathrm{r}$ is the inflection point, which indicates that the community is congested). $\mathrm{AK}{ }^{\wedge} \alpha^{*} \mathrm{~L}^{\wedge} \beta=\mathrm{C}^{*} \mathrm{Nr} * \mathrm{~W}$

$\mathrm{A} / \mathrm{C}=\mathrm{K}^{\wedge} \alpha^{*} \mathrm{~L}^{*} \beta / \mathrm{Nr} * \mathrm{~W}(\mathrm{C}>0, \mathrm{~A}>0)$ Equation on both sides to take the logarithm. Assume that technical progress is neutral, there is $\alpha+\beta=1$, we default that $\alpha=1 / 2, \beta=1 / 2$ and substitute them into the formula, and through the assumption five and the assumption six we can conclude that $\mathrm{KL}=\mathrm{NW}$, that is, production and demand balance. we can figure out that $r=1 / 2$.From the equation we can know that $\mathrm{r}=\mathrm{N} / \mathrm{F}(\mathrm{N})$.

That is when the community congestion rate reached 0.5 , the community reached the optimum scale. Let $\mathrm{t}$ for tax rate, $\mathrm{t}=1-\mathrm{pq} / \mathrm{mw}$, when $\mathrm{pq}=\mathrm{mw}, \mathrm{t}=0$ and when $\mathrm{pq}<\mathrm{mw}, \mathrm{t}>0(1 \geqq \mathrm{t} \geqq 0, \mathrm{p}>0)$. Thus, there are the following decisions.

Table 1

\begin{tabular}{|l|l|l|}
\hline & $\mathrm{T} 1$ & $\mathrm{~T} 2$ \\
\hline $\mathrm{W} 1$ & $\mathrm{~W} 1(1-\mathrm{T} 1),-1 / 2$ & $\mathrm{~W} 1(1-\mathrm{T} 2), 0$ \\
\hline $\mathrm{W} 2$ & $\mathrm{~W} 2(1-\mathrm{T} 1), 1 / 2$ & $\mathrm{~W} 2(1-\mathrm{T} 2), 1$ \\
\hline
\end{tabular}

W1 means low wages, W2 says high wages, T1 is low tax rate, and T2 is high. Under the condition of incomplete information, the wage level is regarded as the expected salary level. A non cooperative 
game between government tax and workers' expectation of wage level is not expected to be any tax at a lower wage level. On the contrary, under high wages, people are willing to accept higher taxes to maximize the effectiveness of their personal utility. Therefore, the community can be used as a part of the public finance income. But the reason why the wage tax model is not sufficient to explain the impact of community economy on taxation under the incomplete information is it can not produce a real tax equalization. That is to say, the establishment of the tax system is not clear at different level of wage expectations.

\section{Conclusions}

Under the condition of complete market, the optimal scale of the community is when the population crowding rate is 0.5 , the enterprise in the community achieves the maximum profit. Community economic scale should be carried out under the optimal size of the community population. Aiming at the problems in the model, the author considers that: 1. Using personal consumption combination to replace the utility and balance the utility of actual income, it can better explain the personal expectations of income and community scale issues. 2. Due to the strict constraints of the assumption, the model is more difficult to carry out. And in view of the author's ability, it can only do a simple discussion. 3. Part of the government revenue and the community members' collective utility lead to the inefficiency because of the different individual endowments, which is the difficulty of the non cooperative game. Perhaps with the help of the methods of social investigation it will reach equilibrium point.

\section{Acknowledgements}

This work is supported by University Planning Funds for "New Silk Road Economic Belt" by Northwest University for Nationalities (Grant XSCZL201602).

\section{References}

[1] Ma Wen. The Social Economics, the Ethnic Publishing Press, Beijing. (2004). (In Chinese).

[2] Guan Yiping. The Introduction of Information Economics, the second edition, The Shanghai Financial University Publishing Press. 7(2002) 1223-12382. (In Chinese)

[3] Lou, Jiade. Lectures of Social Network Analysis, The Social Science Publishing Press, Beijing. (2005). (In Chinese).

[4] Wei Quiling. Handbooks of Sociology, the Social Science Publishing Press, Beijing. (2000). (In Chinese).

[5] Wu Shuiyong. The Institution and Behavior Economics, the Chinese people's University Publishing Press. (2004). (In Chinese)

[6] Zhang Xing. The Public Economics, the Chinese people's University Publishing Press, Beijing. (2000). (In Chinese)

[7] Zhu Dang. The Economic Theory of Network Effect-the market structure of ICT industry: enterprise behavior and public policy, the Chinese people's University Publishing Press, Beijing. (2004). (In Chinese) 